\title{
IMAGEM PARA DEIXAR DE EXISTIR: Possíveis relações entre o dispositivo artístico e o público
}

\section{Imageto cease to exist: \\ Possible relations between the artistic device and the public}

Fabiola Francisca Soares Scaranto ${ }^{1}$ 


\section{Resumo}

Este artigo relata o processo de concepção e inserção do dispositivo artístico interativo Imagem para deixar de existir em espaços expositivos distintos. $O$ texto aborda as relações acionadas deste trabalho inserido em espaços dentro do sistema de arte e também fora do contexto artístico oficial, apontando para as diferenças e as peculiaridades de tais espaços e seu público, assim como essa experiência artística foi significada e significou esses lugares.

Palavras-Chave: Arte, espaço público, institucional, interativo;

\section{Abstract}

This article discusses the the process of created and insertion of the interactive artistic device Image to cease to exist in different exhibition spaces. The text deals with the relations triggered by this work inserted in institutional spaces within the art system and also outside the official artistic context, pointing to the differences and peculiarities of such spaces and their audience and how this artistic experience was meant and meant these places.

Palavras-Chave: Art, public space, institutional, interactive;

ISSN: $1808-3129$

1 Formada em Artes Plásticas pela Universidade do Estado de Santa Catarina em 2006. É mestre e doutoranda pela mesma instituição em Processos Artísticos Contemporâneo. Pesquisa o conceito de ensaio nas artes visuais enquanto prática artística, escrita e suas relações. Estuda também o conceito de temporalidade e impermanência do gesto na relação da passagem entre o vazio e o cheio e o visível e o invisível e seus desdobramentos principalmente por meio do vídeo.Tem experiência no ensino de artes formal e informal e na produção de projetos culturais. Universidade do Estado de Santa Catarina (UDESC) fscaranto@gmail.com 


\section{Introdução}

Desde o início do século XX, as vanguardas buscaram meios que permitissem uma relação mais viva entre espectador e obra. Duchamp, um dos percussores, compreendia o espectador como co-autor da obra ao afirmar, em seu ensaio $O$ Ato criador, que o artista não executa um trabalho sozinho: "o ato criativo não é desempenhado apenas pelo artista; o espectador põe a obra em contato com o mundo exterior ao decifrar e interpretar as suas qualidades internas e, acrescentando, assim a sua contribuição ao ato criativo" (2004, p.73). Taís práticas artísticas fortaleceram-se, sobretudo, em meados do século XX e em diversos segmentos artísticos da época que colocavam o público como parte constituidora de suas obras, como a performance, os happenings, as instalações, land-arts, entre outros.

Umberto Eco também investigou a participação do público em seu livro $A$ obra aberta publicado em 1962. Para Eco, a obra aberta não possui uma forma organizada, mas um campo de possibilidades confiadas à iniciativa do espectador. De acordo com o autor, tal modelo remete a um grupo de obras artísticas que "não reproduz uma suposta estrutura objetiva das obras, mas a estrutura de uma relação fruitiva" (2010, p.29). É importante ressaltar que Eco aponta que todas as obras, mesmo as consideradas tradicionais, são abertas, pois cada interpretação, cada fruição é única, devido à troca particular estabelecida com o indivíduo. "Cada fruição é, assim, uma interpretação e uma execução, pois em cada fruição a obra revive dentro de uma perspectiva original" (2010, p.40). Embora todas as obras de arte sejam essencialmente abertas, o foco deste ensaio volta-se à prática artística que expõe e propõe o processo como centro da obra. Neste sentido, a produção de um dispositivo artístico ${ }^{1}$ como experiência que envolve ativamente o outro, por meio de ações interativas do público é caracterizado, sobretudo, pelo aspecto imprevisivel e movediço de tais práticas. A participação ativa abre-se para experimentação, reflexão, discussão e também para apontar situações e relações humanas não necessariamente relacionadas à arte, como política, cultura, filosofia, meio ambiente, entre outros. O crítico e curador Nicolas Bourriaud assinala que "o campo de intervenção do receptor na obra de arte, hoje consiste numa cultura interativa que apresenta a transitividade do objeto cultural como um fato consumado[...] que ultrapassa o domínio exclusivo da arte" $(2009$, p.36). Bourriaud defende que a "obra se apresenta principalmente como uma duração que deve ser vivida, como uma abertura à discussão ilimitada" (2009, p.24).

Partindo da prática artística como uma duração que deve ser vivida e desse campo de intervenção do receptor na obra de arte, abordarei, neste ensaio, uma experiência artística intitulada Imagem para Deixar de Existir, realizada entre 2011-2014. Esse dispositivo artístico teve a possibilidade de circular em espaços institucionais do sistema da arte como salões e galerias e também inserir-se em espaços fora de qualquer contexto artístico. Tentarei, aqui, pensar não apenas as diferenças e as peculiaridades desses espaços que significaram tal prática artística, mas também como essa prática afetou os espaços em que se inseriu.

1 Abordarei, ao longo do ensaio, essa experiência como um dispositivo, pois, segundo Deleuze (1990), um dispositivo é “ uma espécie de novelo ou meada, um conjunto multilinear [...] que formam processos sempre em desequilíbrio " (p.155). 


\section{Sobre o dispositivo}

O dispositivo Imagem Para Deixar de Existir (2011-2014) configurou-se em desenhos de paisagens em grandes dimensões realizados sobre rolos de papel de 1,50 m de altura que variavam entre $3 \mathrm{~m}$ e $4 \mathrm{~m}$ de comprimento. Os desenhos eram feitos em grafite comum, para que o público pudesse apagá-los com borrachas que eram dispostas ao lado do trabalho. A ação do público era sugerida pelo próprio título do trabalho, que, ao associá-lo à borracha, era convidado a interferir no trabalho. $O$ título, aqui, apresenta-se como um acionador do dispositivo. As palavras usadas para dar nome ao trabalho assemelham-se ao que Bondía descreve "como um criador de sentidos e realidades que muitas vezes funcionam como potentes mecanismos de subjetivação" (2002, p.21). Bondía descreve o processo de nomear ${ }^{2}$ como uma experiência dotada de sentido e não meramente terminológica, assim, o título é redimensionado nessa experiência ao acionar o trabalho e dar sentido à ação do público.

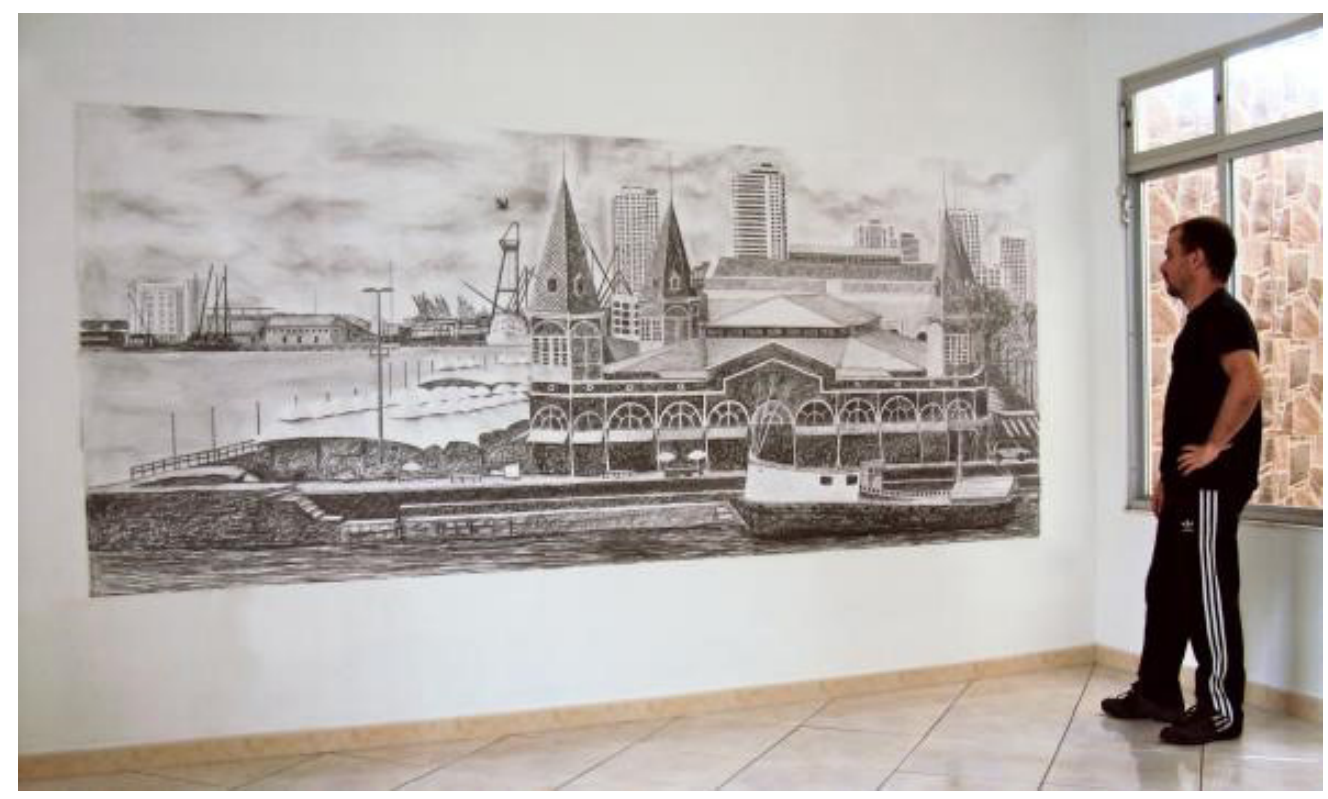

Imagem Para Deixar de Existir, 2011, 350cmx150cm - Ateliê da artista

A proposta de interferência tinha como intenção antecipar, através do gesto de apagar o desenho, a desistência dessa paisagem que deixará de existir pelas transformações constantes da paisagem sob a ação do homem. O registro que deveria, em princípio, caracterizar um gesto de memorização, pois é comum associar o registro como uma tentativa de eternizar algo, ia em direção oposta, quando, ali, ele era feito para ser apagado. Além de propor uma ação de transformação no trabalho, era atribuído, consequentemente, ao gesto um tempo que podia ser sentido ao longo da exposição, através do desaparecimento dos traços, do desgaste da borracha, dos vestígios deixados pela presença do público que, aos poucos, subtraia os desenhos.

2 Quando fazemos coisas com as palavras, do que se trata é de como damos sentido ao que somos e ao que nos acontece, de como correlacionamos as palavras e as coisas, de como nomeamos o que vemos ou que sentimos e de como vemos e sentimos o que nomeamos. (BONDÍA, 2002, p.21) 


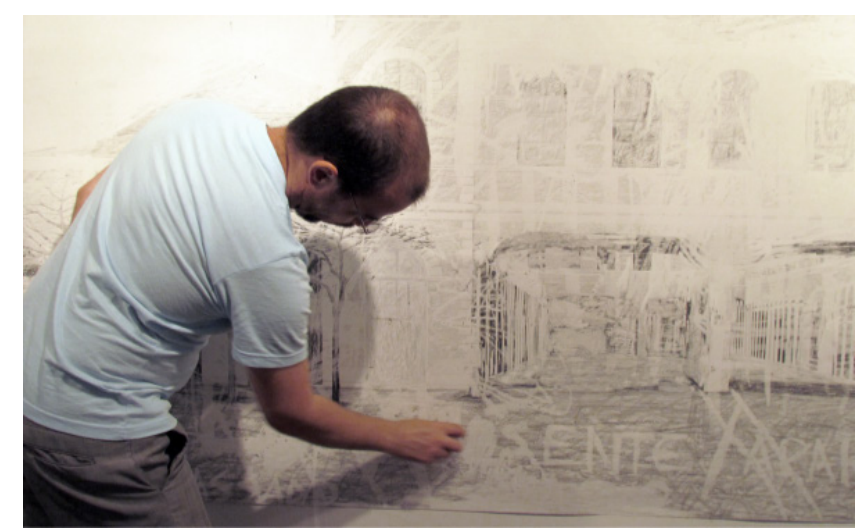

Imagem Para Deixar de Existir, 2012 - Interferência

\section{Experiência no contexto institucional}

Inicialmente, Imagem para Deixar de Existir foi exposto em espaços institucionais como no Salão Arte Pará, em Belém do Pará (2011), onde foram expostos dois desenhos: o Mercado Ver o Peso e a Orla de Belém; e no Museu de Arte Contemporânea, em Mato Grosso do Sul (2011-12), com desenhos de paisagens nativas do estado. A ligação da imagem desenhada ao lugar que o dispositivo é exposto é um fator importante neste projeto, pois o público que circula no espaço da exposição tem alguma identificação com tal imagem. O gesto de apagar torna-se assim mais intimista, pois não é apagado apenas um desenho, mas uma imagem que habita o imaginário local gerando outras possibilidades de significação no gesto de apagar a imagem.

Sobre essa particularidade das relações que podem envolver um dispositivo artístico e o público para o qual ele é destinado, Bourriaud expõe que "a participação que o artista exige do espectador, a natureza das obras, os modelos de sociabilidade propostos ou representados, gerará "um domínio de trocas" particulares. " (2009, p. 24). Neste sentido, Imagem para Deixar de existir assume uma forma e todo o seu valor simbólico particular do lugar em que é exposto para refletir uma realidade de relações humanas, pois, na arte, ainda de acordo com Bourriaud, "toda a representação [...] remete a valores transferíveis à sociedade" (2009, p.25).

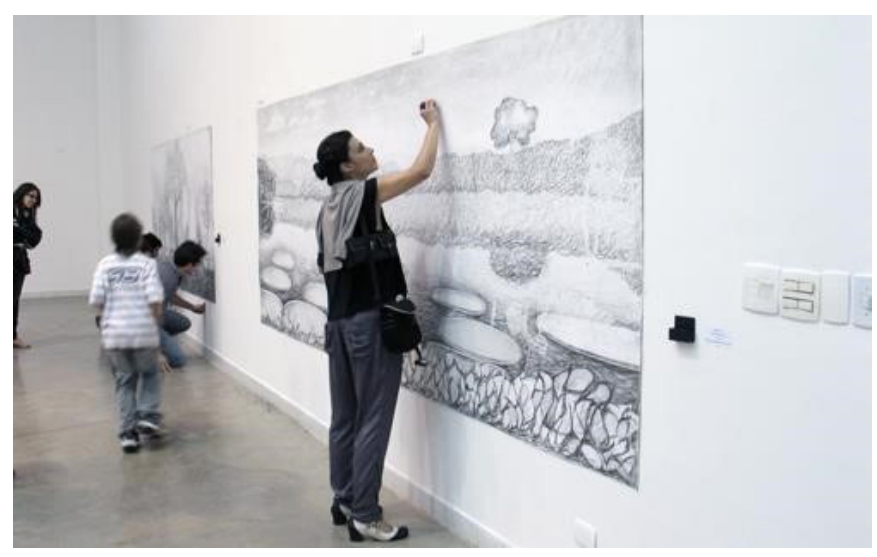

Imagem Para Deixar de Existir, 2011, 400cm×150cm - Marc 
O público tornou-se parte fundamental, pois a decisão de interferência tornava-o responsável por novos desdobramentos que o dispositivo era submetido ao longo de sua exposição, o que lhe atribuía um caráter movediço e imprevisível. O público não somente apagava o desenho, mas interferia de outras formas através da escrita de recados, nomes, palavrões e também por meio de desenhos com formas esquematizadas como símbolos e imagens, muitas das quais com teor obsceno.

Barthes apresenta, em seu ensaio $A$ morte do Autor, que "um texto não é feito de uma linha de palavras, libertando um sentido único, de certo modo teológico (que seria a mensagem do Autor-Deus), mas um espaço de dimensões múltiplas. " (1987, $\mathrm{s} / \mathrm{p}$.). Embora Barthes descreva esse processo na literatura, tal definição estende-se a tudo que envolve o ato ou o processo criativo destinado ao olhar e à apreciação do outro. Assim, na condição de artista, tive que assumir um distanciamento para, de fato, compartilhar a experiência poética e a sua execução, devido à maleabilidade do dispositivo e às diversas possibilidades de ações que o público imprimiu sobre.

Uma das características observadas entre o público e o dispositivo nos espaços institucionais foi o confrontamento pela ação sugerida. Ainda que a interferência não fosse uma imposição, pois o próprio gesto de não interferir também se tornava uma ação, muitos demostravam incômodo com o gesto de apagar. A interferência na imagem também gerou momentos de inquietação em parte do público, principalmente quando o desenho ainda não havia sofrido interferência alguma, causando momentos de tensão entre os presentes. As motivações para a recusa ao gesto eram diversas como considerar agressiva e desrespeitosa a ação sugerida ou mesmo sentimento de pena por apagar um desenho que se notava empenho na sua feitura. Com o decorrer da exposição, quando o desenho começava a perder os seus contornos e as formas à medida que o farelo de borracha acumulava-se no chão, o gesto de apagar tornava-se mais aceitável para o público. A ação passava ser cada vez mais assimilada, revelando novos sentidos por trás do apagamento.

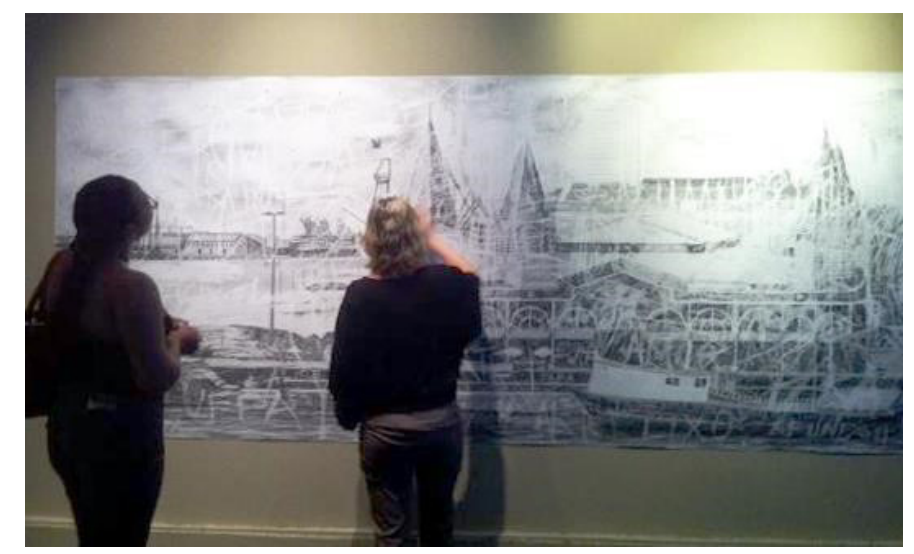

Imagem Para Deixar de Existir, 2012 - Arte Pará

Mais relevante que a interação sugerida, o trabalho foi pensado, sobretudo, como um dispositivo desestabilizador. Esse experimento beira à ponderação de Bishop sobre práticas artísticas coletivas em que "o observador não mais fica coagido a cumprir exigências interativas do artista, mas é pressuposto como um sujeito de pensamento independente, o que é um pré-requisito essencial para a ação política" (BISHOP, 2004, s/p) 
O antagonismo relacional a que me refiro não seria baseado na harmonia social, mas na exposição daquilo que é reprimido ao se sustentar uma aparência de harmonia. Ele, portanto, proveria bases mais concretas a polêmicas para repensar nossa relação com o mundo e uns com os outros. (BISHOP, 2004, s/p)

Outra questão que envolve o trabalho é sua impermanência, devido à materialidade provisória no espaço, indo em direção oposta ao contexto institucional da arte e também do seu mercado. Embora se coloque um dispositivo que, inicialmente, apresenta-se como um objeto artístico aparentemente tradicional, a sua estrutura é corrompida com o gesto de apagar. O objeto é apenas uma parte de um dispositivo que se apresenta na sua totalidade como um processo cuja duração aciona possíveis diálogos e relações com o público que conduz a sua permanência no espaço. Desse modo, sob a ótica do site- specificity de Miown Kwon, "o objeto de arte ou evento nesse contexto é para ser experimentado singularmente no aqui-e-agora pela presença corporal de cada espectador, imediatidade sensorial da extensão espacial e duração temporal" (KWON, p. 167)

Indo contra o menor sentido dos hábitos de desejos institucionais, e continuando a resistir à mercantilização da arte no/para o mercado de arte, a arte site-specific adota estratégias que são ou agressivamente antivisuais - informativas, textuais, expositivas, didáticas - ou imateriais como um todo - gestos, eventos, performances limitadas pelo tempo. O "trabalho" não quer mais ser um substantivo/objeto, mas um verbo/processo, provocando a acuidade crítica (não somente física) do espectador no concerne às condições ideológicas dessa experiência. Nesse contexto, a garantia de uma relação específica entre um trabalho de arte e o seu "site" não está baseada na permanência física dessa relação (conforme exigia Serra, por exemplo), mas antes no reconhecimento da sua impermanência móvel, para ser experimentada como uma situação irrepetível e evanescente. (KWON, pp.170-171)

\section{Experiência no contexto não institucional}

Mesmo nas suas formas mais tradicionais, a arte é relacional em diversos graus. Segundo Bourriaud, "dentro de uma exposição, ainda quando se trate de formas inertes, se estabelece a possibilidade de uma discussão imediata, nos dois sentidos do término: eu percebo, eu comento, e me desloco num mesmo espaço-tempo" (2009, p. 22). Ao deslocar o dispositivo Imagem deixar de existir para fora do contexto tradicional da arte, a relação público e obra foi ressignificada. O espaço de inserção foi a ala norte do Mercado Público ${ }^{3}$ de Florianópolis/SC, um lugar de passagem e de grande circulação de um público caracterizado pela sua diversidade em muitos aspectos. O dispositivo foi exposto na parede do corredor central que atravessa a ala, o que gerou uma descontinuidade nesse lugar de trânsito, atingindo não apenas as pessoas que passavam diariamente ali, mas, principalmente, as pessoas que ali trabalhavam.

\footnotetext{
3 A inserção desse dispositivo na ala norte do Mercado Público partiu de uma proposta enviada ao Território das Artes, evento que ocorreu na cidade de Florianópolis, no início de 2013, em comemoração ao aniversário da cidade, para o qual foram convidados artistas de diversas áreas a proporem interferências artísticas nos espaços públicos da cidade. A escolha do local de inserção foi feita depois de circular pelo centro da cidade de Florianópolis à procura de lugares de grande circulação, chegando a uma grande parede do corredor da ala norte do Mercado Público sem uso algum.
} 
O trabalho provocou, durante o seu tempo de exposição, uma ampla discussão acerca do gesto de apagar uma imagem que carrega um peso simbólico e que, naquele momento, é foco de uma grande polêmica na cidade de Florianópolis, a Ponte Hercílio Luz 4 . Logo que o trabalho foi fixado na parede com a borracha para apagá-lo, formaram-se, entre os comerciantes locais, dois grupos: os que eram favoráveis a apagar a imagem e os que eram contra. Diferente do trabalho exposto nas galerias, as motivações para o gesto ou a sua recusa relacionavam-se não apenas à desconstrução da imagem, mas, principalmente, o que significava apagar a imagem em questão. Não se tratava mais de apagar o desenho, mas apagar a ponte Hercílio Luz, centro de tantas controvérsias sobre a sua permanência ou não como cartão postal e aos altos custos para mantê-la suspensa.

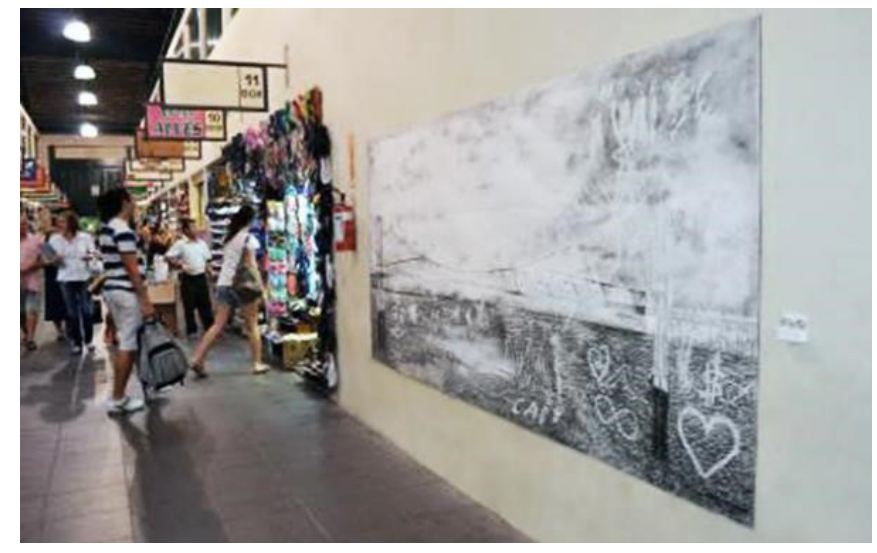

Imagem Para Deixar de Existir, 2013,350cm×150cm - Mercado Público

Os dois grupos formados passaram a dialogar sobre o futuro da ponte: os que defendiam a recuperação da ponte e os que defendiam a destruição dela para a construção de uma nova. Entre os argumentos, muitos acusavam que a permanência da ponte seria mais um meio para desvios de verbas públicas. Outros defendiam a construção de uma nova ponte funcional e não apenas um cartão postal. Os que defendiam a sua restauração argumentavam que a ponte representava a cidade de Florianópolis e a sua destruição significaria uma perda de identidade, por isso, a necessidade dos esforços para a sua preservação.

Segundo Bourriaud,"produzir uma forma é inventar encontros possíveis; receber uma forma é inventar as condições para uma troca"(2009, p.32). Nesse ínterim, a divergência entre os comerciantes acionada pelo dispositivo gerou novas relações entre as pessoas que ali trabalhavam, ao mesmo tempo em que se criou uma ruptura entre os comerciantes, essa mesma divisão aproximou-os no seu convívio. A inserção do dispositivo no Mercado Público e o valor simbólico da imagem desenhada

\footnotetext{
$4 \quad$ A ponte Hercílio Luz é centro de um grande impasse entre especialistas, governo, mídia e população de Florianópolis. Em seus 90 anos de existência, completos em 2016, a ponte já está interditada a mais de 30 anos, devido a sérios problemas estruturais. Durante todos esses anos, a ponte sofreu poucas intervenções para resolver os problemas estruturais que, ao longo dos anos, pioraram, expondo novos problemas estruturais, tornando a sua recuperação quase impossível e a custos altos que os governos estadual, federal e municipal custam a financiar. Segundo muitos especialistas, como engenheiros que tiveram contato direto com os problemas que a ponte sofre, afirmam que investir tanto dinheiro na reforma é um absurdo do ponto de vista técnico e que a cidade de Florianópolis tem outras necessidades como escolas, postos de saúde e hospitais, sendo um absurdo gastar milhões para apenas pendurar luzes, pois mesmo reformada a ponte não serviria mais para a mobilidade urbana. No entanto, a questão é complicada, pois a ponte tem "componentes românticos e laços fortes com os moradores da cidade". A vida útil de uma ponte de concreto é de aproximadamente quatro décadas. A Hercílio Luz já tem mais que o dobro. Especialistas afirmam que a Ponte pode ruir durante a própria restauração. Inclusive rajadas de vento intenso podem levar a ponte a cair. Mais informações: http://ndonline. com.br/florianopolis/noticias/23476-ponte-hercilio-luz-completa-tres-decadas-de-agonia.html
} 
instauraram, no lugar, um espaço de troca, em que as pessoas projetavam, no trabalho, os seus desejos e as suas frustrações. Ainda de acordo com Bourriaud, "a forma é o horizonte a partir do qual a imagem pode ter um sentido, indicando um mundo desejado, suscetível de ser discutido pelo espectador, sendo a partir desta discussão que o desejo próprio do espectador pode aflorar" (2009, p.32).

Outra situação acionada foi a posição de mediação que os dois grupos assumiram entre o dispositivo e o público que passava pelo local. Como intermediários do trabalho, cada grupo defendia o seu posicionamento na tentativa de convencer o público a interferir ou não no desenho, gerando, assim, uma espécie de jogo, como se o gesto de apagar atingisse diretamente a ponte. No entanto, o desenho lentamente foi desaparecendo durante as semanas que se seguiram e assim como ocorreu no espaço institucional, o dispositivo também tornou-se um suporte canalizador através de palavras e mensagem de apoio e crítica à ponte.

Através da obra de arte o artista estabelece um diálogo. A essência da prática artística se radicaria então na invenção de relações entre sujeitos, cada obra de arte representaria a proposição de habitar um mundo em comum, e o trabalho de cada artista, um feixe de relações com o mundo que por sua vez gera outras relações, e assim infinitamente. (BOURRIAUD, 2009)

O dispositivo foi ressignificado nesse lugar de passagem. Durante algumas semanas, criou-se o que Bourriaud (2009) define como interstício social ${ }^{5}$, um espaço de relações humanas, pois proporcionou "outras possibilidades de troca" entre esse público. Ao final, quando o trabalho foi retirado do corredor, houve uma manifestação de pesar por parte dos comerciantes que haviam se apegado ao trabalho, mesmo sendo, naquela altura, apenas um fantasma da imagem inicial.

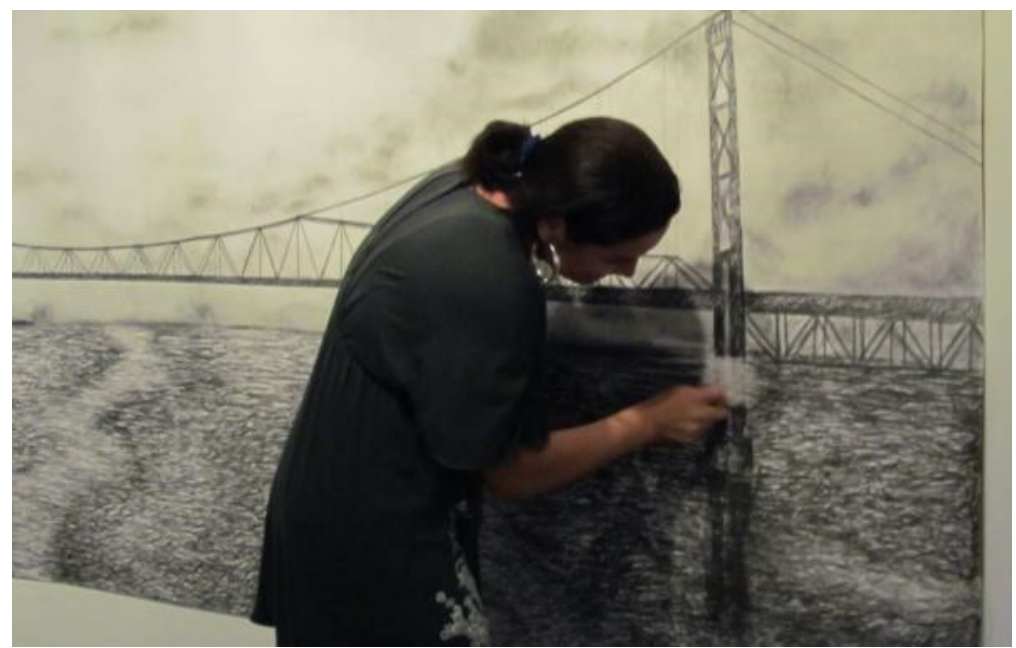

Imagem Para Deixar de Existir, 2013 - Mercado Público

$5 \quad$ O termo interstício foi usado por Karl Marx para designar comunidades de troca que escapavam ao quadro da economia capitalista, pois não obedeciam à lei do lucro: escambo, vendas com prejuízo, produções autárquicas etc. O interstício é um espaço de relações humanas que, mesmo inserido de maneira mais ou menos aberta e harmoniosa no sistema global, sugere outras possibilidades de troca, além das vigentes nesse sistema. É exatamente essa a natureza da exposição de arte contemporânea no campo do comércio das representações: ela cria espaços livres, gera durações com um ritmo contrário ao das durações que ordenam a vida cotidiana, favorece um intercâmbio humano diferente das zonas de comunicação que nos é imposta. BOURRIAUD, 2009, pp. 22-23. 
Embora o trabalho tenha sido apenas temporário, a sua receptividade e repercussão foram bastante significativas despertando o interesse da direção do Mercado Público e da secretaria de cultura do município na ativação permanente do espaço para exposição da produção artística local. Em 2015, foi inaugurado no mesmo espaço o Mural da Cultura6 , após uma grande reforma do Mercado Público de adequação do local e recuperação da arquitetura original da época da construção do Mercado.

\section{Considerações}

A intenção de relatar essa experiência, que circulou no espaço comum e institucionalizado, foi apresentar as possibilidades e as particularidades que ela acionou nesses lugares e não apenas privilegiar um em detrimento do outro. Embora tenha se tratado de um trabalho efêmero, abriu-se ao diálogo e a diferentes perspectivas da relação entre o público e o dispositivo.

[...] as propostas relacionais em sua forma complexa transitam tanto pelos marcos convencionalizados da instituição Arte quanto se aproximam de acontecimentos e situações inseridos nos mundos de vida cotidiana, disponibilizando ao artista novas possibilidades de atuação no Real que materializam espaços de vida que gerem participação, reflexão e diálogo a partir do convívio. Enfim, geram relações de descontinuidade onde a subjetividade dos sujeitos envolvidos pode ser reconstruída. Sua forma de representar cria um corte momentâneo sobre determinado contexto, ampliando nossa visão e fazendo com que a realidade possa ser vista e vivida de outras maneiras.(KINCELER, ALTHAUSEN, DAMÉ, 2002, p.85)

As relações entre o dispositivo e o público que se criaram nesses espaços foram muito distintas, mesmo tratando-se, inicialmente, da mesma experiência. A principal distinção percebida foi as motivações que levaram o público a apagar o dispositivo. No espaço institucionalizado, o gesto de apagar o trabalho apresentou-se mais relacionado à própria ação de interferência num trabalho dentro de um espaço no qual o comportamento do público é formalizado por convenções universais, como não tocar ou aproximar-se de um trabalho de arte, que, em geral, deve ser observado a certa distância. A ação tornava-se mais difícil, pois o trabalho, na sua forma e montagem, apresentava-se como um trabalho convencional, cercado por outros trabalhos em geral, também convencionais, gerando, em princípio, certo desconforto no público. No entanto, com o decorrer da exposição, essa postura transformava-se à medida que o desenho sumia pela ação. O receio inicial dava espaço para uma postura mais ativa e incisiva do público, que tornava o dispositivo um lugar para extravasar, através de outras formas de intervenção, além de apenas apagar o desenho.

No espaço não convencional, o corredor do Mercado Público de Florianópolis, a relação entre o público e o dispositivo girou em torno do apego simbólico à imagem desenhada, a Ponte Hercílio Luz. O gesto de interferir na imagem vinculava-se mais ao significado da imagem representada do que a relação com o seu suporte. Assim, a ação desse público em particular carregava diversas marcas, produzindo outros tipos de relações, diferentes do espaço da galeria. Sobre essas marcas do público, Bourriaud expõe: 
[...] o que o espectador traz é todo o seu corpo, sua história e seu comportamento, e não mais uma simples presença física abstrata". [...] O encontro com a obra gera uma duração mais do que um espaço. Tempo de manipulação, de compreensão, de tomada de decisões, que ultrapassa o ato de "completar a obra com olhar. (BOURRIAUD, 2009, p.83)

Como já ressaltado, mais do que discutir as diferenças entre a experiência no espaço institucional e não institucional, o objetivo foi perceber como o dispositivo atingiu, de maneira peculiar, o público de ambos os lugares e como esses públicos imprimiram as suas especificidades no dispositivo. Portanto, como afirma Bishop, "as tarefas que se colocam diante de nós atualmente são analisar como a arte contemporânea se dirige ao observador e avaliar a qualidade das relações com o público que ela produz. " $(2004, \mathrm{~s} / \mathrm{p})$. Neste caso, essas relações manifestaram-se através de um fazer compartilhado do trabalho. $O$ trabalho não se apresentou como um objeto pronto, mas como um processo aberto ao outro e, sobretudo, dependente dele, desse modo, atribuiu outra dimensão ao público que atuou diretamente na experiência da construção ou, no caso, da desconstrução da imagem.

\section{Referências Bibliográficas}

BARTHES, Roland. A morte do autor e Da obra ao texto In: O rumor da língua. São Paulo/ Campinas: Brasiliense/ Ed. Da Unicamp, 1988.

BISHOP, Claire, 2004. Antagonismo e Estética Relacional. Tatuí, revista (October n.110 2004). Disponível: http://revistatatui.com/revista/tatui-12/claire-bishop/

BONDÍA, Jorge Larrosa. Notas sobre a experiência e o saber de experiência. Revista Brasileira de Educação, n. 19, p. 20-28, jan./fev./mar./abr. 2002.

BOURRIAUD, Nicolas. Estética Relacional. São Paulo: Martins, 2009.

DELEUZE, Gilles. ¿Que és un dispositivo? In: Michel Foucault, filósofo. Barcelona: Gedisa, 1990, pp. 155-161. Tradução de Wanderson Flor do Nascimento.DUCHAMP, Marcel. O Ato Criativo. In: BATTCOCK, Gregory (org.). A nova arte. São Paulo:Perspectiva, 2004.

DUCHAMP, Marcel. O Ato Criador In: BATTCOCK, Gregory. A Nova Arte. São Paulo. Perspectiva: 2004

ECO, Umberto. Obra aberta: forma e indeterminação nas poéticas contemporâneas. São Paulo: Perspectiva, 2010.

KINCELER, José L.,ALTHAUSEN, Gabriela, DAMÉ, Paulo. Desestabilizando os limites - Artes Relaciona em sua Forma Complexa. In: Seção Artefato do site Rizoma.net, 2002. Disponível em:http://pt.scribd.com/doc/46875547/Artefato-Rizoma-net 
KWON, Miwon. Um lugar após o outro: anotações sobre site-specificity. Revista do Programa de Pós-Graduação em Artes Visuais - EBA - UFRJ, Rio de Janeiro, n.17, ano XV, p. 167-187, 2008.

PARRAMON, Ramon. Arte, Participación y Espacio Público.In: Models de participacióenxarxa, Jornada D'innovació estratégica. 2003. Disponível em: http://www. insumisos.com/lecturasinsumisas/Espacio\%20publico\%20y\%20participacion.pdf 